\begin{tabular}{|c|l|}
\hline Title & A re Moderate Leviathans Harmful to Tax Coordination? \\
\hline Author(s) & Itaya, Jun-ichi; Chikara, Y amaguchi \\
\hline Citation & Discussion Paper, Series A, 325, 1-9 \\
\hline Issue Date & 2018-05 \\
\hline Doc URL & http://hdl.handle.net/2115/70230 \\
\hline Type & bulletin (article) \\
\hline File Information & DPA 325.pdf \\
\hline
\end{tabular}

Instructions for use 
Discussion Paper, Series A, No.2018-325

Are Moderate Leviathans Harmful to Tax

Coordination?

Jun-ichi Itaya

Chikara Yamaguchi

May.2018

Faculty of Economics and Business

Hokkaido University

Kita 9 Nishi 7, Kita-Ku, Sapporo 060-0809, JAPAN 


\title{
Are Moderate Leviathans Harmful to Tax Coordination?*
}

\author{
Jun-ichi Itaya $^{\dagger}$ and Chikara Yamaguchi ${ }^{\ddagger}$
}

May 6, 2018

\begin{abstract}
This paper investigates how the sustainability of partial tax coordination between several governments is affected when the governments' objective function is moderate Leviathan in that policymakers are neither entirely benevolent nor fully self-interested. We show that partial tax coordination is more likely to prevail when moderate Leviathan-type governments become more revenue-maximizing Leviathans. In this case, the increased intensity of fiscal externality due to different tax rates makes partial tax coordination more sustainable at the cost of the tax union member countries' well-being.
\end{abstract}

JEL classification: $\mathrm{H} 71 ; \mathrm{H} 73 ; \mathrm{F} 59$

Keywords: Tax coordination; moderate Leviathan; tax competition

\footnotetext{
${ }^{*}$ This work is supported by JSPS KAKENHI grant number 16K03727.

${ }^{\dagger}$ Graduate School of Economics and Business Administration, Hokkaido University, Sapporo 060-0809, Japan. Tel.: +81-11-706-2858; Fax: +81-11-706-4947; E-mail: itaya@econ.hokudai.ac.jp

${ }^{\ddagger}$ Corresponding author, Graduate School of Social Sciences, Hiroshima University, 1-2-1 Kagamiyama, HigashiHiroshima 739-8525, Japan. Tel.: +81-82-424-7297; Fax: +81-82-424-7212; E-mail: chikaray@hiroshima-u.ac.jp
} 


\section{Introduction}

Coordination of the tax policies of sovereign jurisdictions has often been considered a remedy against inefficiently low taxes due to mobile tax bases induced by tax competition. Konrad and Schjelderup (1999) and Bucovetsky (2009) demonstrate that when governments maximize the welfare of residents, partial tax coordination mitigates the downward pressure on capital taxation and improves the welfare of the tax union members as well as non-members in a one-shot tax competition game. Itaya, Okamura, and Yamaguchi (2014), on the other hand, show that partial tax coordination can be sustained as a subgame perfect Nash equilibrium in a repeated game setting in which governments maximize their discounted total tax revenues and increased intensity of tax competition makes partial tax coordination more sustainable.

Recently, Edwards and Keen (1996), Pal and Sharma (2013), and Wrede (1998) have suggested the moderate Leviathan approach where policymakers are neither entirely benevolent nor fully selfinterested as an objective of governments confronted by tax competition. This type of government would be more realistic than the pure Leviathan or benevolent governments and might reflect the recent developments in the political economics literature (see, e.g., Persson and Tabellini, 2002), which endogenously explains the formation of economic policy. This paper addresses how the sustainability of partial tax coordination between several moderate Leviathan-type governments is affected when they become more Leviathan and enhance the motive of tax-revenue maximizing. We show that when the objective of moderate Leviathan-type governments is expressed by a linear combination of tax revenue and the utility of a representative resident, stronger Leviathan preferences for tax revenue intensify race-to-the-bottom competition because fiscal externality is enhanced and Nash punishments against the deviator from tax coordination become harsher. This harsher punishment makes partial tax coordination more sustainable, but has an adverse effect on the well-being of residents in the tax union member countries.

The remainder of the paper is organized as follows. Section 2 presents a one-shot tax competition model and characterizes its non-cooperative solution. Section 3 constructs a repeated interactions partial tax coordination model in which a subset of countries agree to implement a common tax rate, whereas countries outside the tax union do not, and investigates how stronger government concern about tax revenue affects the sustainability of partial tax coordination in a repeated tax competition game setting. Section 4 offers some policy implications. 


\section{The model}

Consider an economy composed of $N$ identical countries. The countries are indexed by the subscript $i \in \mathbf{N}=\{1, \cdots, N\}$. In each country, there exist a national government, a continuum of households, and a continuum of firms; households are immobile across countries, but capital is perfectly mobile. These factors are utilized in the production of a numéraire good using the quadratic production technology $f\left(k_{i}\right) \equiv\left(A-k_{i}\right) k_{i}$, where $A>0$ is a productivity parameter and $k_{i}$ is the capital per capita demanded in country $i$. We assume that $A>2 k_{i}$ to ensure that the marginal productivity of capital is always positive. Public expenditure, denoted by $g_{i}$, is fully financed by a source-based tax on capital $\tau_{i}$ such that the government's budget constraint $i$ is $g_{i}=\tau_{i} k_{i}$. Given the market prices and tax rates, firms choose their inputs to maximize profits, $\pi_{i}=f\left(k_{i}\right)-w_{i}-\left(r+\tau_{i}\right) k_{i}$, where $r$ is the net return on capital and $w_{i}$ is the country-specific wage rate. Then, profit-maximizing behavior can be characterized by the first-order conditions $r=f^{\prime}\left(k_{i}\right)-\tau_{i}=A-2 k_{i}-\tau_{i}$ and $w_{i}=f\left(k_{i}\right)-k_{i} f^{\prime}\left(k_{i}\right)=k_{i}^{2}$. Each competitive firm employs capital until its marginal productivity $f^{\prime}\left(k_{i}\right)$ is equal to the cost of capital $r+\tau_{i}$ and labor such that the marginal productivity of labor $f\left(k_{i}\right)-k_{i} f^{\prime}\left(k_{i}\right)$ is equal to the wage rate $w_{i}$. Perfect international mobility of capital ensures that the net return on capital $r$ is equalized across all countries, and with the capital market equilibrium condition $\sum k_{i}=N \bar{k}$, we can explicitly solve the equilibrium net return on capital as follows:

$$
r^{*}=A-2 \bar{k}-\bar{\tau},
$$

where $\bar{\tau} \equiv\left(\sum_{\forall i \in \mathbf{N}} \tau_{i}\right) / N$ is the average capital tax rate for all countries and $\bar{k}$ represents the identical capital endowment of each country. By substituting $r^{*}$ in (1) into $r=A-2 k_{i}-\tau_{i}$ and solving for $k_{i}$, we obtain the demand for capital:

$$
k_{i}^{*}=\bar{k}+\frac{\bar{\tau}-\tau_{i}}{2}
$$

The residents of all countries are identical in terms of capital endowment and preferences; the preference of a resident in country $i$ can be simply represented by the linear utility function $u\left(c_{i}\right) \equiv c_{i}$, where $c_{i}$ is resident $i$ 's private consumption of the numéraire good. They inelastically supply one unit of labor to domestic firms and invest their capital endowments in home and/or foreign countries. Since the government of country $i$ provides public expenditure $g_{i}$ (or a lump-sum income transfer) to its residents, the residents' budget constraint can be expressed as $c_{i}=w_{i}+r^{*} \bar{k}+g_{i}$. 
The government in every country is assumed to behave as a moderate Leviathan deriving utility from the total amount of public expenditure $g_{i}$ (i.e., the tax revenue) as well as from the well-being of the representative resident $u\left(c_{i}\right)$ (see, e.g., Edward and Keen, 1996; Wrede, 1998; Pal and Sharma, 2013). More specifically, its objective function is assumed to be a linear combination of $g_{i}$ and $u\left(c_{i}\right)$ : $V_{i} \equiv \theta g_{i}+(1-\theta) u\left(c_{i}\right)$, where $\theta \in(0,1)$ is a weight parameter attached to the tax revenue exogenously fixed through time and identical across countries. Note also that a moderate Leviathan government acts perfectly benevolent when $\theta=0$ or like a pure Leviathan when $\theta=1$. The government chooses $\tau_{i}$ so as to maximize $V_{i} \equiv \theta g_{i}+(1-\theta) c_{i}$ subject to $c_{i}=f\left(k_{i}^{*}\right)-k_{i} f^{\prime}\left(k_{i}^{*}\right)+r^{*} \bar{k}+g_{i}=f\left(k_{i}^{*}\right)+r^{*}\left(\bar{k}-k_{i}^{*}\right)$ and $g_{i}=\tau_{i} k_{i}^{*}$. The first-order condition reads

$$
-\frac{\tau_{i}}{k_{i}^{*}} \frac{\partial k_{i}^{*}}{\partial \tau_{i}}=\theta+(1-\theta)\left(\frac{\bar{k}}{k_{i}^{*}}-1\right) \frac{\partial r^{*}}{\partial \tau_{i}}
$$

Since countries are identical, that is, $k_{i}^{*}=\bar{k},(3)$ boils down to

$$
-\frac{\tau_{i}}{k_{i}^{*}} \frac{\partial k_{i}^{*}}{\partial \tau_{i}}=\frac{\tau_{i}}{\bar{k}} \frac{N-1}{2 N}=\theta
$$

whose first equality follows from differentiating $k_{i}^{*}$ in (2) with respect to $\tau_{i}$. (4) implies that the optimal tax should be chosen such that the elasticity of capital (i.e., $\left.-\left(\tau_{i} / k_{i}^{*}\right)\left(\partial k_{i}^{*} / \partial \tau_{i}\right)\right)$ equals $\theta$. By solving (4) for the $N$-country Nash equilibrium tax rate $\tau^{N E}$, we obtain

$$
\tau^{N E}=\frac{2 N \theta}{N-1} \bar{k}
$$

It is clear that as the government's preferences for tax revenue, $\theta$, becomes stronger, the chosen tax rate increases because the tax revenue is highly appreciated. Note also that since every country chooses the same tax rate $\tau^{N E}$ in a symmetric $N$-country Nash equilibrium, there is no capital trade between countries, thus eliminating the terms of trade effect. The corresponding welfare level of governments, on the other hand, is given by $V^{N E}=\theta \tau^{N E} \bar{k}+(1-\theta) f(\bar{k})$. Moreover, we have

$$
\frac{d V^{N E}}{d \theta}=\frac{4 N \theta}{N-1} \bar{k}^{2}-(A-\bar{k}) \bar{k} \gtreqless 0 \text { if and only } A \lesseqgtr \frac{(4 N \theta+N-1) \bar{k}}{N-1} .
$$

This ambiguous sign stems from the conflicting effects of increasing $\theta$ on tax revenue and the wellbeing of residents. 


\section{Partial tax coordination}

To describe the cooperative phase of the infinitely repeated tax competition game, we use the concept subgroup Nash equilibrium suggested by Konrad and Schjelderup (1999). According to them, a subgroup Nash equilibrium occurs when a subset of countries, denoted by $\mathbf{S}=\{1, \cdots, S\} \subsetneq \mathbf{N}$ with $S \geq 2$, forms only one subcoalition to coordinate their capital tax policies, while the rest of the countries, that is, the complementary set $\mathbf{N} / \mathbf{S}=\{S+1, \cdots, N\} \neq \emptyset$, behave individually and non-cooperatively. The tax union consisting of country $i \in \mathbf{S}$ chooses a capital tax rate that will maximize the sum of their objectives, $V_{\mathbf{S}} \equiv \sum_{h \in \mathbf{S}} V_{h}$, which yields the first-order condition for a coalition member

$$
\theta\left(\bar{k}+\frac{\bar{\tau}-\tau_{i}}{2}\right)-\frac{N-1}{2 N} \tau_{i}+\frac{1}{2 N} \sum_{h \neq i, h \in \mathbf{S}} \tau_{h}+\frac{1-\theta}{N} \sum_{h \in \mathbf{S}}\left(\frac{\bar{\tau}-\tau_{h}}{2}\right)=0
$$

while the non-coalition member $i \in \mathbf{N} / \mathbf{S}$ individually behaves in line with the best-response function (3), that is,

$$
\theta \bar{k}+\frac{(N-1) \theta+1}{2 N}\left(\bar{\tau}-\tau_{i}\right)-\frac{N-1}{2 N} \tau_{i}=0
$$

which is obtained by substituting (1), (2), (4), and $d r^{*} / d \tau$ into (3). By solving the system of eqs. (7) and (8) and applying symmetry inside and outside the tax union, respectively (i.e., $\tau_{i}=\tau_{\mathbf{S}}^{C}$ for $\forall i \in \mathbf{S}$ and $\tau_{i}=\tau_{\mathbf{S}}^{C}$ for $\forall i \in \mathbf{N} / \mathbf{S}$ ), we obtain the following subgroup Nash equilibrium tax rates for the coalition and non-coalition members, respectively:

$$
\begin{aligned}
\tau_{\mathbf{S}}^{C} & =\frac{2 \theta \bar{k}\left\{N^{2}+(N-S)(S-1)+\theta[N(N-S)+S(S-1)]\right\}}{(N-S)[(1+\theta)(N-1)+S]}, \\
\tau_{\mathbf{N} / \mathbf{S}}^{C} & =\frac{2 \theta \bar{k}\left\{N^{2}-S(S-1)+\theta[N(N-S)+S(S-1)]\right\}}{(N-S)[(1+\theta)(N-1)+S]}
\end{aligned}
$$

where it is immediately seen that $\tau_{\mathbf{S}}^{C}>\tau_{\mathbf{N} / \mathbf{S}}^{C}$ for $\theta>0$. The point to be noticed is that the subgroup Nash equilibrium is asymmetric to the extent that the tax union and the rest of the countries will have different objective functions as well as different capital endowments, and therefore, they will set different tax rates so as to manipulate the terms of trade effect in their favor as well as to internalize fiscal externality.

We next investigate under what condition one can sustain partial tax coordination in a repeated tax competition game. For analytical simplicity, we assume that every country possesses a common actual discount factor, $\delta \in(0,1)$. In every period, each member country coordinates its tax rate at 
$\tau_{\mathbf{S}}^{C}$ given that all the other member countries chose $\tau_{\mathbf{S}}^{C}$ in the previous period. If a member country deviated from this in the previous period, the tax union would collapse, triggering a punishment phase that results in the $N$-country Nash equilibrium from now on. Thus, the grim trigger strategies constitute a Nash equilibrium of the repeated game if

$$
\frac{1}{1-\delta} V_{\mathbf{S}}^{C} \geq V_{i}^{D}+\frac{\delta}{1-\delta} V^{N E}
$$

where the welfare functions of the moderate Leviathan-type government $i$ associated with coordination, unilateral deviation, and punishment phases of the repeated game are denoted by $V_{\mathbf{S}}^{C}, V_{i}^{D}$, and $V^{N E}$, respectively. $V_{\mathbf{S}}^{C}$ can be computed from (9) and (10). To compute $V_{i}^{D}$, we need to know the best-deviation tax rate of the potential defector $i, \tau_{i}^{D}$, given that $S-1$ members and $N-S$ non-members follow $\tau_{\mathbf{S}}^{C}$ and $\tau_{\mathbf{N} / \mathbf{S}}^{C}$, respectively:

$$
\tau_{i}^{D}=\frac{2 \theta \bar{k} \Delta}{(N-1)(N-S)[(1+\theta) N+1-\theta][(1+\theta)(N-1)+S]}
$$

where $\Delta \equiv N^{2}(1+\theta)\left[N(N-\theta S)+\theta(N-1)^{2}-S^{2}(1-\theta)\right]+N(S-1)(N-1+\theta)+S(1-\theta) \times$ $[(S-1)(1-\theta)-\theta N(N-2 S+1)]>0$. Following some manipulation, we can confirm that $V_{\mathbf{S}}^{C}>$ $V^{N E}$ and $V_{i}^{D}>V_{\mathbf{S}}^{C}$ for $\theta>0$ (this can be indirectly confirmed by inspecting the numerator and denominator of (14)); thus, each member country clearly has an incentive to deviate from the coordinated tax rate $\tau_{\mathbf{S}}^{C}$ without future punishments. Moreover, a straightforward comparison of the tax rates such as (5), (9), (10), and (12) reveals the following lemma:

Lemma 1 For $\theta>0$, the ranking of the tax rates set in the respective phases is given by

$$
\tau^{N E}<\tau_{i}^{D}<\tau_{\mathbf{N} / \mathbf{S}}^{C}<\tau_{\mathbf{S}}^{C}
$$

The tax union raises its tax rate $\tau_{\mathbf{S}}^{C}$ in order to internalize fiscal externality, while the non-member countries also raise their tax rates $\tau_{\mathbf{N} / \mathbf{S}}^{C}$ because of strategic complementarity compared to the $N$ country Nash equilibrium tax rate $\tau^{N E}$. From (11) and the tax rates set in the respective phases of the repeated game, we can obtain the minimum discount factor of the union members as follows:

$$
\delta \geq \delta^{*} \equiv \frac{V_{i}^{D}-V_{\mathbf{S}}^{C}}{V_{i}^{D}-V^{N E}}=\frac{N^{2}(S-1)[N+\theta(N-1)]^{2}}{[N(S-1)+S(1+\theta(N-1))] \Theta}
$$

where $\Theta \equiv \theta\left\{(N-S)\left[2 N^{2}+(N-1)(N+S)\right]+N^{2}(N-3)+S(N+1)\right\}+N^{3}-S^{2}+2 \theta^{2}(N-$ 
$S)(N-1)^{2}>0$. More importantly, it is straightforward to verify that $\delta^{*}<1$ so long as $S<N$. Taken together, we summarize our main findings as follows:

Proposition 1 (i) If the actual discount factors of all tax-union member countries are sufficiently close to 1, partial tax coordination can be sustained as a subgame perfect Nash equilibrium of the repeated game irrespective of the size of the coalition (except for the coalition of all countries);

(ii) The larger $\theta$ is, the more it is likely to sustain partial tax coordination; and

(iii) As $\theta$ becomes larger, the residents' well-being (consumption) in the member countries becomes worse off, whereas that in the non-member countries becomes better off.

Proof. Statement (i) follows from the Folk theorem, which is confirmed by checking $\delta^{*}<1$ in (14). To prove (ii), we differentiate $\delta^{*}$ in (14) with respect to $\theta$, to obtain

$$
\frac{d \delta^{*}}{d \theta}=-\frac{2 N^{2}(N-1)(N-S)(S-1)[N+\theta(N-1)] \Omega}{[N(S-1)+S(1+\theta(N-1))]^{2} \Theta^{2}}<0
$$

where $\Omega \equiv S(N+1)\left(N^{2}-S+1\right)-N+\theta S(N-1)\left(3 N^{2}+N-S\right)+\theta^{2} S(N-1)^{2}[3 N+\theta(N-1)]>0$. To prove (iii), we differentiate the utilities of the member and non-member countries, respectively, as follows:

$$
\begin{aligned}
\frac{d u_{\mathbf{S}}^{C}}{d \theta} & \equiv \frac{d c_{\mathbf{S}}^{C}}{d \theta}=-\frac{2 \theta \bar{k}^{2}(S-1)\left\{\Delta+N^{2}\left[S\left(2-\theta^{2}\right)-1\right]+N\left(\theta^{2} S^{2}+1\right)\right\}}{(N-S)[(1+\theta)(N-1)+S]^{3}}<0, \\
\frac{d u_{\mathbf{N} / \mathbf{S}}^{C}}{d \theta} & \equiv \frac{d c_{\mathbf{N} / \mathbf{S}}^{C}}{d \theta}=\frac{2 \theta \bar{k}^{2} S(S-1)\left\{\Delta+N S(N-S)\left(1-\theta^{2}\right)\right\}}{(N-S)^{2}[(1+\theta)(N-1)+S]^{3}}>0
\end{aligned}
$$

where $\Delta \equiv(1+\theta)(2+\theta)\left[N^{2}(N-1)-S(S-1)\right]+S[N(N-1)-S(S-1)]+3 S(S-1)(1+\theta S)>0$.

Several remarks are in order. First, since the tax union has chosen higher $\tau_{\mathbf{S}}^{C}$ in order to internalize fiscal externality within the tax union, the tax union is a capital exporter preferring a higher capital price, that is, a lower tax rate, whereas the outside countries act as a capital importer preferring a lower capital price, that is, a higher tax rate. In this situation, a larger $\theta$ induces all countries to further raise their tax rates because the tax revenue is highly appreciated. Thus, from (1), it follows that $d r^{C} / d \theta<0$. The decrease in capital price $r^{C}$ reduces the well-being of residents in the union member countries, but improves it in the non-union member countries. In response, the tax union member countries raise their tax rates more than the non-member countries do, because for the governments of the member countries, tax revenue has more weight than the well-being of residents. 
Indeed, the tax differential between these countries will be enlarged:

$$
\frac{d\left(\tau_{\mathbf{S}}^{C}-\tau_{\mathbf{N} / \mathbf{S}}^{C}\right)}{d \theta}=\frac{2 \bar{k} N(N-1)(S-1)(N+S-1)}{(N-S)[(1+\theta)(N-1)+S]^{2}}>0 .
$$

This wider tax wedge leads to $d\left(k_{\mathbf{N} / \mathbf{S}}^{C}-k_{\mathbf{S}}^{C}\right) / d \theta>0$ due to $(2)$; that is, the tax union member countries export more capital, whereas the non-member countries import more capital. Thus, the national income and thus consumption level of the member countries shrink, whereas those of the non-member countries expand. Linear utility results in statement (iii).

To intuitively understand statements (i) and (ii), we first decompose the impacts of changes $\theta$ on the government's objective as follows:

$$
\begin{aligned}
& \frac{d V^{N E}}{d \theta}=g^{N E}+\underbrace{\theta \underbrace{\frac{d g^{N E}}{d \theta}}}_{(+)}-c^{N E}, \\
& \frac{d V_{\mathbf{S}}^{C}}{d \theta}=g_{\mathbf{S}}^{C}+\theta \underbrace{\frac{d g_{\mathbf{S}}^{C}}{d \theta}}_{(+)}+(1-\theta) \underbrace{\frac{d c_{\mathbf{S}}^{C}}{d \theta}}_{(-)}-c_{\mathbf{S}}^{C}, \\
& \frac{d V_{i}^{D}}{d \theta}=g_{i}^{D}+\theta \underbrace{\frac{d g_{i}^{D}}{d \theta}}_{(+)}+(1-\theta) \underbrace{\frac{d c_{i}^{D}}{d \theta}}_{(+)}-c_{i}^{D},
\end{aligned}
$$

where $g^{N E} \equiv \tau^{N E} \bar{k}, g_{\mathbf{S}}^{C} \equiv \tau_{\mathbf{S}}^{C} k_{\mathbf{S}}^{C}$, and $g_{i}^{D} \equiv \tau_{i}^{D} k_{i}^{D}$. It is straightforward to confirm that $d g^{N E} / d \theta>$ $0, d g_{\mathbf{S}}^{C} / d \theta>0, d g_{i}^{D} / d \theta>0$, and $c_{i}^{D}>c^{N E}>c_{\mathbf{S}}^{C} \cdot{ }^{1}$ Moreover, recalling that $\delta^{*}<1$, we obtain $V_{i}^{D}-V^{N E}-\left(V_{i}^{D}-V_{\mathbf{S}}^{C}\right)>0$; or equivalently,

$$
\theta g_{i}^{D}+(1-\theta) c_{i}^{D}-\left[\theta g^{N E}+(1-\theta) c^{N E}\right]-\left[\theta g_{i}^{D}+(1-\theta) c_{i}^{D}\right]+\left[\theta g_{\mathbf{S}}^{C}+(1-\theta) c_{\mathbf{S}}^{C}\right]>0 .
$$

When $\theta \in(0,1], g_{i}^{D}-g^{N E}>g_{i}^{D}-g_{\mathbf{S}}^{C}$, while $c_{i}^{D}-c^{N E}<c_{i}^{D}-c_{\mathbf{S}}^{C}$. These facts, together with (20), imply that as long as $\theta>0$, the difference in tax revenues outweighs that in utilities (=consumptions). (15) can be alternatively expressed by

$$
\frac{d \delta^{*}}{d \theta}=\frac{V_{i}^{D}-V_{\mathbf{S}}^{C}}{\left(V_{i}^{D}-V^{N E}\right)^{2}}\left[\left(\frac{d V_{i}^{D}}{d \theta}-\frac{d V_{\mathbf{S}}^{C}}{d \theta}\right)-\delta^{*}\left(\frac{d V_{i}^{D}}{d \theta}-\frac{d V^{N E}}{d \theta}\right)\right]<0,
$$

which amounts to

$$
\left(\frac{d V_{i}^{D}}{d \theta}-\frac{d V_{\mathbf{S}}^{C}}{d \theta}\right)-\delta^{*}\left(\frac{d V_{i}^{D}}{d \theta}-\frac{d V^{N E}}{d \theta}\right)<0,
$$

\footnotetext{
${ }^{1}$ Detailed derivations of these impacts are available upon request from the corresponding author.
} 
since $V_{i}^{D}-V_{\mathbf{S}}^{C}>0$. Further, because both terms in (21) are positive and $\delta^{*}<1,(21)$ leads to

$$
\left(\frac{d V_{i}^{D}}{d \theta}-\frac{d V_{\mathbf{S}}^{C}}{d \theta}\right)-\left(\frac{d V_{i}^{D}}{d \theta}-\frac{d V^{N E}}{d \theta}\right)<0
$$

which, using (17), (18), and (19), can be expressed as

$$
\begin{aligned}
\frac{d V_{i}^{D}}{d \theta}-\frac{d V^{N E}}{d \theta}-\left(\frac{d V_{i}^{D}}{d \theta}-\frac{d V_{\mathbf{S}}^{C}}{d \theta}\right)= & \underbrace{g_{i}^{D}-g^{N E}-\left(g_{i}^{D}-g_{\mathbf{S}}^{C}\right)}_{(+)}-\underbrace{\left(c_{i}^{D}-c^{N E}\right)-\left(c_{i}^{D}-c_{\mathbf{S}}^{C}\right)}_{(+)} \\
& -\underbrace{\frac{d g^{N E}}{d \theta}}_{(+)}+\theta \underbrace{\frac{d g_{\mathbf{S}}^{C}}{d \theta}}_{(+)}+(1-\theta) \underbrace{\frac{d c_{\mathbf{S}}^{C}}{d \theta}}_{(-)}>0 .
\end{aligned}
$$

From (22), the tax revenue difference $g_{i}^{D}-g^{N E}>0$ relative to $g_{i}^{D}-g_{\mathbf{S}}^{C}>0$ overweighs other effects appearing on its RHS; more specifically, the positive sign of (22) is due to the significantly lower size of the tax revenue in the Nash equilibrium, $g^{N E}\left(\equiv \tau^{N E} \bar{k}\right)$, relative to that in the cooperative phase, $g_{\mathbf{S}}^{C}$, because the $N$-country Nash equilibrium tax rate $\tau^{N E}$ is smaller than the other tax rates as shown in (13), and because the tax base (i.e., $\bar{k}$ ) is unaffected by tax changes.

For more insightful interpretation, we further rewrite the definition of the minimum discount factor in (14) as follows:

$$
\frac{\delta^{*}}{1-\delta^{*}}\left(V_{\mathbf{S}}^{C}-V^{N E}\right)=V_{i}^{D}-V_{\mathbf{S}}^{C}
$$

where the $L H S$ represents the one-period loss accrued to the punishment phase (i.e., $V_{\mathbf{S}}^{C}-V^{N E}$ ), while the $R H S$ represents the immediate gain from unilateral deviation (i.e., $V_{i}^{D}-V_{\mathbf{S}}^{C}$ ). Although both sides increase in $\theta,(15)$ indicates that the increase in loss is more than the increase in gain. This implies the impact of increasing $\theta$ will be less on $V^{N E}$ than on $V_{\mathbf{S}}^{C}$. This is because the well-being of residents (i.e., $c^{N E} \equiv f(\bar{k})$ ) will be unaffected by tax changes and also the effect of increasing $\theta$ will be relatively weaker on $g^{N E}$ than on $g_{\mathbf{S}}^{C}$ for the reasons stated above. In short, the increase in $\theta$ tends to intensify tax competition in the $N$-country Nash equilibrium thereby not improving $V^{N E}$ much compared to $V_{\mathbf{S}}^{C}$; this ends up makes punishments relatively harsher thus deterring the incentive of deviation of union members.

\section{Concluding remarks}

What lesson should we draw from Proposition 1? A trade-off exists between the sustainability of tax coordination and the well-being of residents in the tax union member countries; in other words, 
there is a trade-off between the well-being of residents and the tax revenue which would represent the private interests of politicians, bureaucrats or lobbying groups. This finding has a very significant implication from the political economic point of view in that if governments become more Leviathan in preferences or are more inclined to maximize tax revenue, they are more likely to lose office in the next election due to loss of popularity among voters from heavier tax burdens and deteriorating wellbeing of voters. Although the residents of the union member countries benefit from tax coordination internalizing fiscal externality, enhancing the sustainability of tax coordination too much or placing too much weight on tax revenues could make it more difficult for policymakers to get re-elected or promoted, thereby preventing continuation of the same tax policy and thus jeopardizing the sustainability of tax coordination.

\section{References}

Bucovetsky, S. (1991) Asymmetric tax competition, Journal of Urban Economics 30, 167-181.

Edwards, J., and M. Keen (1996) Tax competition and Leviathan, European Economic Review 40, 113-134.

Itaya, J., M. Okamura, and C. Yamaguchi (2014) Partial tax coordination in a repeated game setting? European Journal of Political Economy 34, 263-278.

Konrad, K.A., and G. Schjelderup (1999) Fortress building in global tax competition, Journal of Urban Economics 46, 156-167.

Pal, R., and A. Sharma (2013) Endogenizing governments' objectives in tax competition, Regional Science and Urban Economics 43, 570-578.

Persson, T., and G. Tabellini (2002) Political Economics: Explaining Economic Policy, The MIT Press.

Wrede, M. (1998) Household mobility and the moderate Leviathan: efficiency and decentralization, Regional Science and Urban Economics 28, 315-328. 